\title{
Performance analysis and enhancement of direct power control of DFIG based wind system
}

\author{
Mohamed Amine Beniss, Hassan El Moussaoui, Tijani Lamhamdi, Hassane El Markhi \\ Electrical Department, Intelligent systems, geosources and renewable energy laboratory, Faculty of Sciences and \\ Technologies, Sidi Mohamed Ben Abdellah University, Fez, Morocco
}

\begin{abstract}
Article Info
Article history:

Received Sep 16, 2020

Revised Jan 15, 2019

Accepted Apr 20, 2021

\section{Keywords:}

Active and reactive powers

Direct power control

Doubly fed induction generator

ABSTRACT

The paper proposes a complete modeling and control technique of variable speed wind turbine system (WTS) based on the doubly fed induction generator (DFIG). Two levels back-to-back converter is used to ensure the energy transfer between the DFIG rotor and the grid. The wind turbine to operate efficiently, a maximum power point tracking (MPPT) algorithm is implemented. Then, direct power control (DPC) strategy has been combined with the MPPT technique in order to guarantee the selection of the appropriate rotor voltage vectors and to minimize the active and reactive power errors. Finally, the simulation is performed by using MATLAB/simulink platform basing on $7.5 \mathrm{KW}$ DFIG wind generation system, and the results prove the effectiveness of our proposed control technique.
\end{abstract} MPPT

Wind energy conversion system
This is an open access article under the $\underline{C C B Y-S A}$ license.

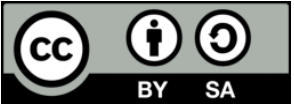

\section{Corresponding Author:}

Mohamed Amine Beniss

Electrical Department

Intelligent systems, geosources and renewable energy laboratory

Faculty of Sciences and Technologies

Sidi Mohamed Ben Abdellah University, Fez, Morocco

Email: Mohamedamine.beniss@usmba.ac.ma

\section{INTRODUCTION}

In the last few decades, the dangers of fossil fuel exhaustion have led research centers and companies involved in the field of renewable energy to offer more affordable and less expensive technical solutions. Among these solutions, the doubly fed induction generators (DFIG) which is become extensively employed in the wind power generation systems. This is due to their remarkable characteristics compared to the permanent magnet synchronous generator (PMSG) [1]. Some of these characteristics are the adaptability with variable wind speed by simply changing the rotor operating frequency and the regulation of the active and reactive power injected into the grid. Also, the converter related to the rotor is designed to support energy exchange rates between $25 \%$ and $30 \%$ of the generator's global energy [2]. Many research works have addressed the control of DFIG, the most known strategies are the field-oriented control (FOC), the direct torque control (DTC) and the direct power control (DPC) [3], [4].

The first method has some difficulties, among them, the necessity to use coordinate transformations, the current PI regulators must be tuned and they depend strongly on DFIG parameters, in other words, this method is not robust. The DTC strategy has been introduced in the aim to overcome these problems [5]. It is known for being performing, robust and less sensitive to parameters variations of the DFIG. Unfortunately, the high ripple in developed torque and power, in addition to the non-constant switching frequency led to a non-linear behavior in the torque and the power hysteresis comparators. The progress of power electronics permitted the emergence of rapid switches, this has enabled the development of new control strategies such 
as the direct power control (DPC) Figure 1 [12], [3]. This method has mitigated considerably the problems mentioned.

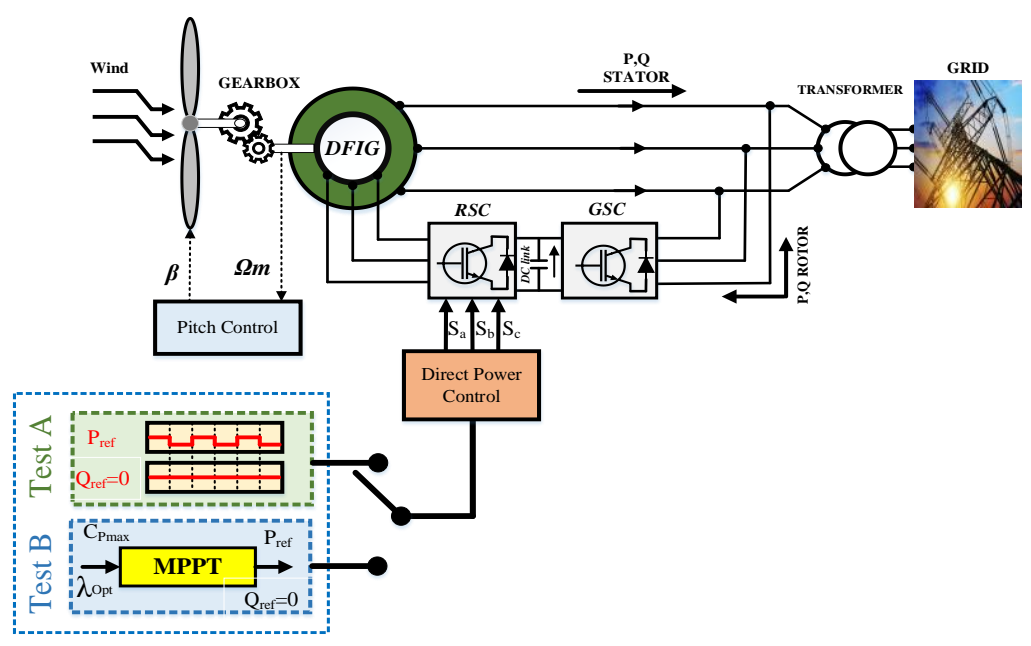

Figure 1. Schematic diagram of the DFIG-based wind energy generation system

The existing DPC strategies are classified into two major categories; the voltage-based DPC and virtual flux-based DPC [6]. Figure 2 gives more details about the different sub-classes of these control strategies. Our proposal aims to analyze and enhance the performances of classical DPC. Also, the assessment of the DFIG response to a variable wind profile [7].

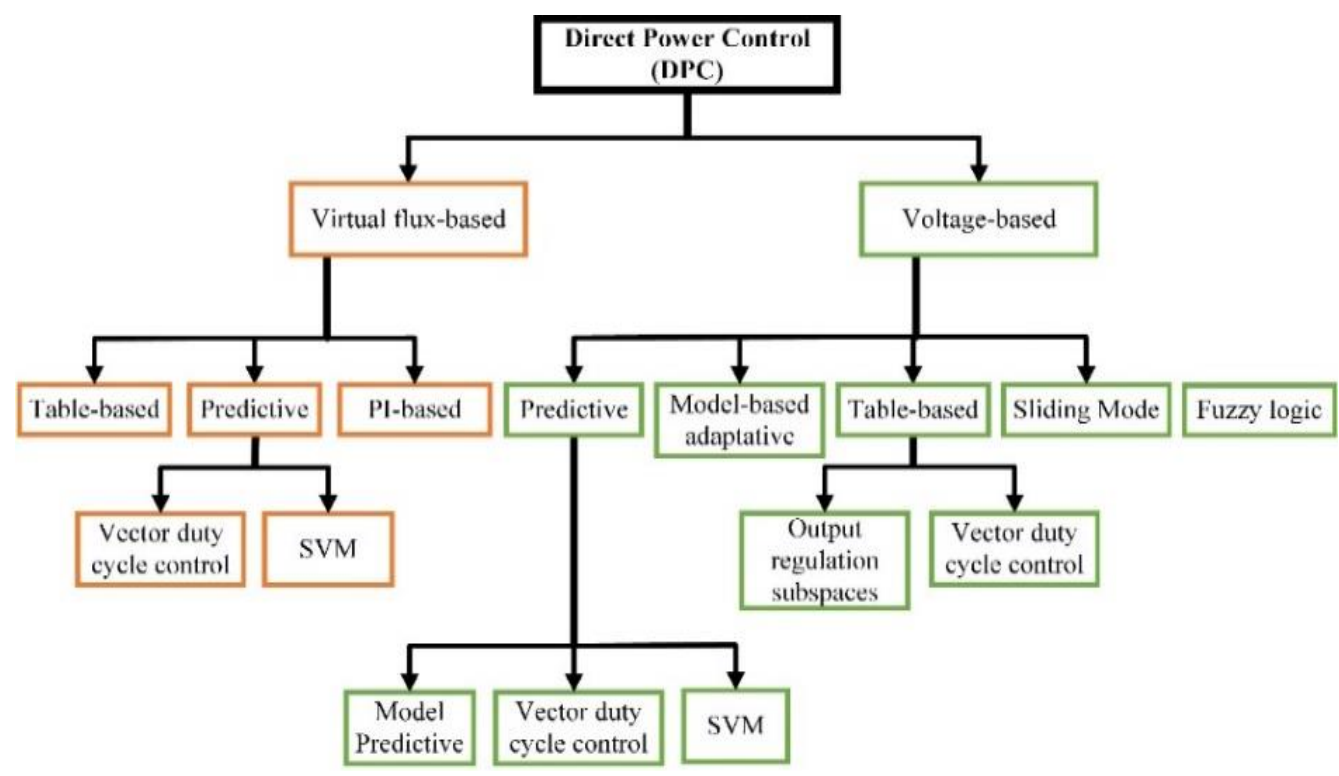

Figure 2. Block diagram of DPC strategies

This paper aims generally the study of the direct power control strategy (reactive-active) applied to the rotor-side converter (RSC). The main contributions of this work are, a) design of direct power control strategy that ensures a high level of performances, b) guarantee the extraction of the maximum power and reaching a unit power factor by a decoupled control of active and reactive powers, and c) applying a fixed and aleatory wind profile to wind energy conversion system to assess its capability in different usage situations.

The remainder of this article is organized as follows: First, Section 2 presents the model of the 
studied wind energy conversion system. Then, section 3 describes the adopted DPC strategy. After that, Section 4 discusses the simulation results. Finally, section 5 provides some conclusions of this work.

\section{MODEL OF THE WIND ENERGY CONVERSION SYSTEM}

\subsection{Mathematical model of the wind turbine}

The wind turbine aerodynamic input power can be expressed as [8]-[10].

$$
P_{V}=\frac{1}{2} \cdot \rho \cdot \mathrm{S} \cdot V^{3}
$$

where $\rho$ refer to the air density, while $S$ represents the area of the wind wheel, $V$ denotes wind speed.

The formula expresses the mechanical power gained by the turbine from the aerodynamic input power.

$$
P_{m e c}=C_{P}(\lambda, \beta) \cdot P_{V}=\frac{1}{2} \cdot C_{P}(\lambda, \beta) \cdot \rho \cdot \mathrm{S} \cdot V^{3}
$$

Where the coefficient $C_{P}$ represents the efficiency of the wind turbine blades. It is a function of $\lambda$ and $\beta$ which refer respectively to the tip speed ratio and the blade pitch angle. The parameter $\lambda$ can be obtained by using (3).

$$
\lambda=\frac{\Omega_{t} R}{V}
$$

With:

$\mathrm{R}$ : the blade radius.

$\Omega_{t}$ : The angular speed of the turbine.

The function $\mathrm{C}_{\mathrm{P}}$ can be approximated by this well-known expression [1], [8].

$$
\left.C_{P}=0.5-0.0167 \cdot(\beta-2)\right) \cdot \sin \left(\frac{\pi \cdot(\lambda+0.1)}{10.5-0.3 \cdot(\beta-2)}\right)
$$

The coefficient $C_{P}$ reaches it maximum value $C_{P \max }=0.4998$ when $\beta=0$ degree and $\lambda=8.095$. Based on this point one can define the rotor speed that corresponds to the (MPPT) [9]. Figure 3 depicts the time variation of the power coefficient $\mathrm{C}_{\mathrm{P}}$. This result has been obtained after the simulation of our system, the simulation curve of $C_{P}$ Figure 3 proves the robustness of our MPPT algorithm. The $C_{P}$ maximum value is maintained at about 0.4985 despite the variation of the wind speed [8], [11].

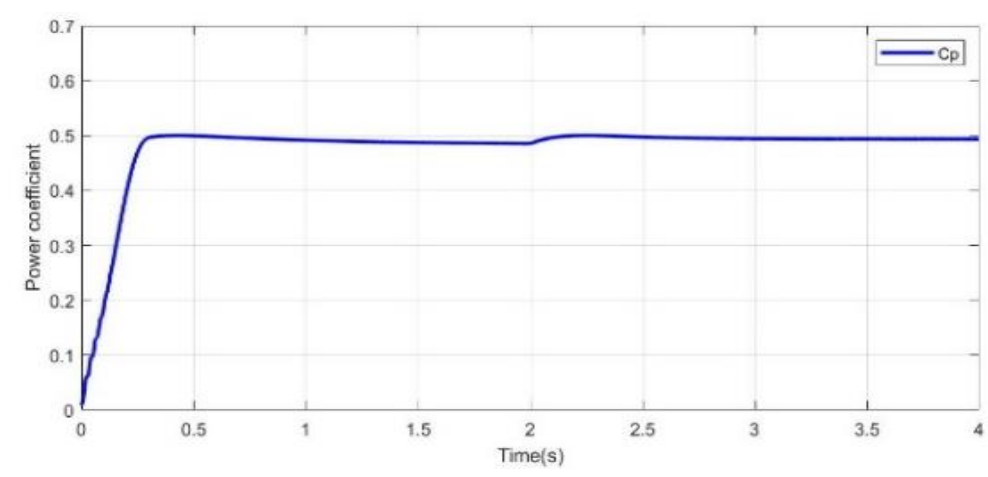

Figure 3. Power coefficient $\left(C_{P}\right)$

\subsection{DFIG modeling}

Many research works have been devoted to the modeling of wind power generators. Especially the 
DFIG, in order to simplify the control of the DFIG we have to model the system in the two-phase reference Figure 4 [12]. By using Park transformation, we convert the three-phase representation of the system to another one in the d-q frame. Thus, the overall electrical model can be obtained. The explain this clearly [3], [13], [14].

- Voltages across the stator terminals

$$
\left\{\begin{array}{l}
V_{s d}=R_{s} i_{s d}+\frac{d \psi_{s d}}{d t}-\omega_{s} \cdot \psi_{s q} \\
V_{s q}=R_{s} i_{s q}+\frac{d \psi_{s q}}{d t}+\omega_{s} \cdot \psi_{s d}
\end{array}\right.
$$

- Voltages across the rotor terminals

$$
\left\{\begin{array}{l}
V_{r d}=R_{r} \cdot i_{r d}+\frac{d \psi_{r d}}{d t}-\omega_{r} \cdot \psi_{r q} \\
V_{r q}=R_{r} \cdot i_{r q}+\frac{d \psi_{r q}}{d t}+\omega_{r} \cdot \psi_{r d}
\end{array}\right.
$$

With: $\omega_{s}-\omega_{r}=\omega_{m}$

The basic magnetic equations related to the flux expressions in the reference frame $(\mathrm{d}, \mathrm{q})$ are given as.

- Flux at the stator

$$
\left\{\begin{array}{l}
\psi_{s d}=L_{s} i_{s d}+M . i_{r d} \\
\psi_{s q}=L_{s} i_{s q}+M . i_{r q}
\end{array}\right.
$$

- Flux at the rotor

$$
\left\{\begin{array}{l}
\psi_{r d}=L_{r} i_{r d}+M . i_{s d} \\
\psi_{r q}=L_{r} i_{r q}+M . i_{s q}
\end{array}\right.
$$
by [15].

The electromagnetic torque expression as a function of the rotor flux and the rotor currents is given

$$
C_{e m}=\frac{3}{2} \mathrm{p}\left(\mathrm{I}_{r q} \psi_{r d}-I_{r d} \psi_{r q}\right)
$$

By using the fundamental equation of dynamics, we deduce [16].

$$
C_{m}-C_{e m}-f_{v} \Omega_{m e c}=J \frac{d \Omega_{m e c}}{d t}
$$

Where $C_{m}, f_{v}$ and $J$ are respectively the mechanical torque applied to the DFIG, the viscous friction and the wind turbine inertia.

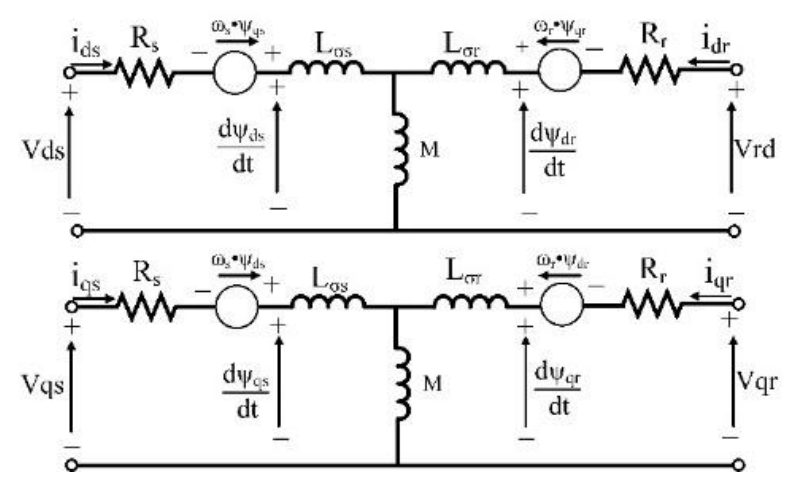

Figure 4. d-q equivalent circuit of the DFIG in synchronous coordinates 


\subsection{Voltage converter modeling}

In this subsection, the IGBT transistors are considered as ideal switches. Consequently, one can derive the relationship between control configurations and the electrical voltages of the AC and DC sides of the inverter. The general topology of the two-level voltage source inverter (VSI) is shown in Figure 5 each inverter arm contains two electronic switches IGBT [25].

All the information mentioned are summarized in the mathematical model [17]-[19].

$$
\left[\begin{array}{l}
V_{a r} \\
V_{b r} \\
V_{c r}
\end{array}\right]=\frac{U_{C}}{3}\left[\begin{array}{ccc}
2 & -1 & -1 \\
-1 & 2 & -1 \\
-1 & -1 & 2
\end{array}\right]\left[\begin{array}{l}
S_{1} \\
S_{2} \\
S_{3}
\end{array}\right]
$$

Where, $\mathrm{V}_{\mathrm{ar}}, \mathrm{V}_{\mathrm{br}}$, and $\mathrm{V}_{\mathrm{cr}}$ are are the output voltages of the inverter.

It is underlined here that the switches states can be represented by three Boolean variables such as, a) $\mathrm{Si}=1$ if $\bar{T}_{i}$ is closed and $T_{i}$ is open, and b) $\mathrm{Si}=0$ if $\bar{T}_{i}$ is open and $T_{i}$ is closed. With $(i=1,2,3)$.

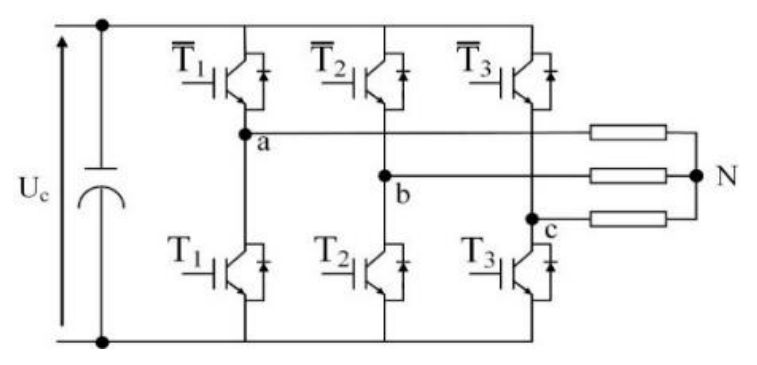

Figure 5. Simplified topology of the two-level VSI

\section{DPC CONTROL STRATEGY}

\subsection{DPC principal}

The DPC strategy aims to directly control the stator active and reactive power of the DFIG [24]. It is based on the change of the rotor flux vector in the $d-q$ coordinates. This can be done by controlling the voltage vector at the output of the rotor side converter (RSC). As mentioned before the control of IGBTs generates the desired voltage vector [13], [20].

To select the appropriate state of the converter's switches. The instantaneous sector zone of the rotor's vector flux, the error between the real active power and the reference one and the error between the estimated reactive power and its reference must be calculated. Two hysteresis comparators are used to guarantee that both powers are confined between the predefined upper and the lower bounds. These operating steps are illustrated more clearly in Figure 6 [21].

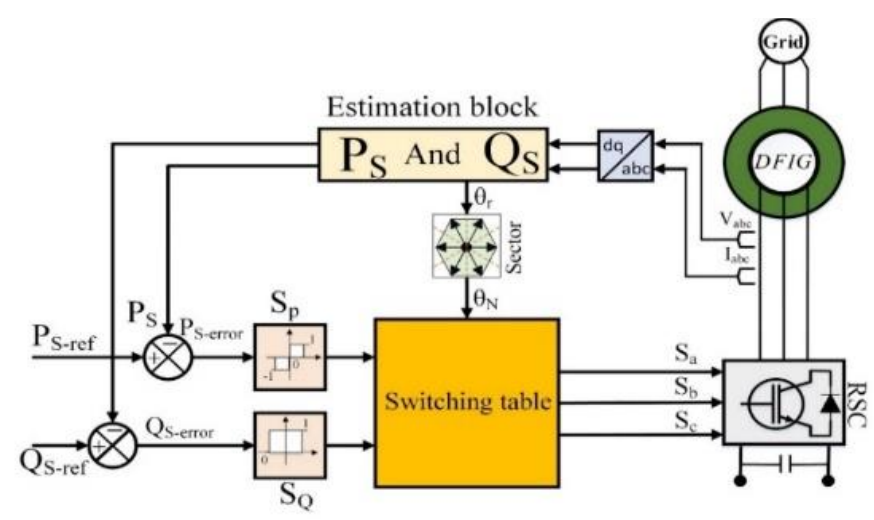

Figure 6. Detailed scheme of the DPC strategy 


\subsection{Active and reactive powers formulation}

The expression of the rotor vector voltage can be formulated as [13], [17].

$$
\vec{V}_{r}=\sqrt{(3 / 2)} U_{c}\left(\mathrm{~S}_{1}+\mathrm{S}_{2} e^{(\mathrm{j} 2 \pi / 3)}+\mathrm{S}_{3} e^{(\mathrm{j} 2 \pi / 3)}\right)
$$

Figure 7 displays all possible orientations of the voltage applied to the rotor. It is noticed that there are eight different voltage possibilities two of them are zero vectors $\left(V_{0}\right.$ and $\left.V_{7}\right)$.

At this stage, we establish the mathematical relationship between rotor flux and voltage in the d-q reference frame.

$$
\vec{V}_{r}^{r}=R_{r} \vec{i}_{r}^{r}+\frac{d \vec{\psi}_{r}^{r}}{d t}
$$

For the sake of simplicity, we neglect the rotor resistance for the high and medium power machines (6).

$$
\vec{V}_{r}^{r}=\frac{d \vec{\psi}_{r}^{r}}{d t}
$$

Knowing that both simulation platforms and electronic calculation units work in discrete time. The (6) needs to be discretized. Therefore, applying this process to (6) yields.

$$
\int_{0}^{T_{0}} \vec{V}_{r}^{r}=\vec{\psi}_{r}^{r}(\text { fin })-\vec{\psi}_{r}^{r} \text { (int) }
$$

We obtain:

$$
\vec{\psi}_{r}^{r}(\text { fin })-\vec{\psi}_{r}^{r}(\text { int })=\vec{V}_{r}^{r} T_{0}
$$

The (16) and (17) give the expression of stator active and reactive powers in the d-q reference frame, respectively.

$$
\begin{aligned}
& P_{s}=\frac{3}{2}\left(\mathrm{~V}_{s d} I_{s d}+V_{s d} I_{s q}\right) \\
& Q_{s}=\frac{3}{2}\left(\mathrm{~V}_{s d} I_{s d}-V_{s d} I_{s q}\right)
\end{aligned}
$$
results [13].

After the development and simplification of the equations mentioned before, we can obtain the

$$
\begin{aligned}
& P_{s}=K_{1}\left|\vec{\psi}_{r}\right| \sin (\delta) \\
& Q_{s}=K_{2}\left[K_{3}-\left|\vec{\psi}_{r}\right| \cos (\delta)\right]
\end{aligned}
$$

$K_{1}, K_{2}$ and $K_{3}$ are constant parameters of appropriate dimensions. It is remarkable that changing $\left|\vec{\psi}_{r}\right| \sin (\delta)$ and $\left|\vec{\psi}_{r}\right| \cos (\delta)$ will influence $P_{s}$ and $Q_{s}$. Figure 8 graphically explains the equations. It clearly shows how the rotor voltage vector can modify the direction and magnitude of the rotor flux. The module and the phase of the rotor flux in the $\mathrm{d}-\mathrm{q}$ reference frame are provided by.

$$
\begin{aligned}
& \theta_{r}=\arctan \left(\frac{\psi_{r d}}{\psi_{r q}}\right) \\
& \psi_{r}=\sqrt{\psi_{r d}^{2}+\psi_{r q}^{2}}
\end{aligned}
$$




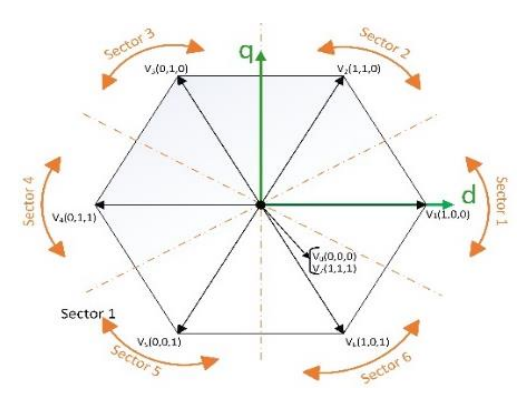

Figure 7. Voltage vectors delivered by the inverter

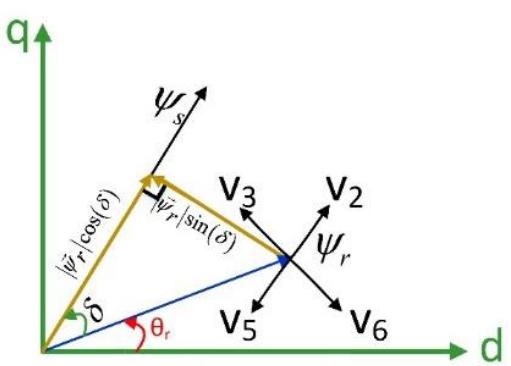

Figure 8. Vector diagram describing some possibilities for changing the location of the rotor flux

\subsection{Hysteresis power regulators}

Many solutions offer the possibility of maintaining very efficient operation of the DFIG, but among them, the use of two or three-level hysteresis regulators remains the most appropriate choice for controlling the active and reactive power levels. By inserting these comparators in the DPC diagram, we guarantee that the exchange of active and reactive power between the DFIG and the grid follows the reference values. Hence, the selection of a rotor voltage vector must reduce errors between the measured and the reference powers (active and reactive) and confine them between the hysteresis upper and lower bounds [22] [9]. To maintain $\mathrm{Q}_{\mathrm{s}}$ between the desirable bounds, we choose a two-level hysteresis regulator as depicted in Figure 9. The Boolean function $\mathrm{S}_{\mathrm{Q}}$ increase $\mathrm{Q}_{\mathrm{S}}$ when its value is equal " 1 " and decrease $\mathrm{Q}_{\mathrm{S}}$ otherwise. Here are the instructions that control the behavior of the hysteresis regulator at two levels.

$$
\left\{\begin{array}{l}
\text { if } \Delta Q \succ \varepsilon_{Q} \Rightarrow S_{Q}=1 \\
\text { if }-\varepsilon_{Q} \leq \Delta Q \leq \varepsilon_{Q} \text { and } \frac{\Delta Q}{d t} \succ 0 \Rightarrow S_{Q}=0 \\
\text { if }-\varepsilon_{Q} \leq \Delta Q \leq \varepsilon_{Q} \text { and } \frac{\Delta Q}{d t} \prec 0 \Rightarrow S_{Q}=1 \\
\text { if } \Delta Q \prec-\varepsilon_{Q} \Rightarrow S_{Q}=0
\end{array}\right.
$$

While to control the active power $P_{S}$ we use Three-level hysteresis regulator as displayed by Figure 10 . In this case, the function $\mathrm{S}_{\mathrm{P}}$ can take three values: if " 1 " increase $P_{s}$,"-1" decrease $P_{s}$, and " 0 " to hold $\mathrm{P}_{\mathrm{S}}$. The algorithm contains the instructions that govern the functioning of the three-level:

$$
\left\{\begin{array}{l}
\text { if } \Delta P \succ \varepsilon_{P} \Rightarrow S_{P}=1 \\
\text { if } 0 \leq \Delta P \leq \varepsilon_{P} \text { and } \frac{\Delta P}{d t} \succ 0 \Rightarrow S_{P}=0 \\
\text { if } 0 \leq \Delta P \leq \varepsilon_{P} \text { and } \frac{\Delta Q}{d t} \prec 0 \Rightarrow S_{P}=1 \\
\text { if } \Delta P \prec-\varepsilon_{p} \Rightarrow S_{P}=-1 \\
\text { if }-\varepsilon_{p} \leq \Delta P \leq 0 \text { and } \frac{\Delta P}{d t} \succ 0 \Rightarrow S_{P}=0 \\
\text { if }-\varepsilon_{P} \leq \Delta P \leq 0 \text { and } \frac{\Delta P}{d t} \prec 0 \Rightarrow S_{P}=-1
\end{array}\right.
$$

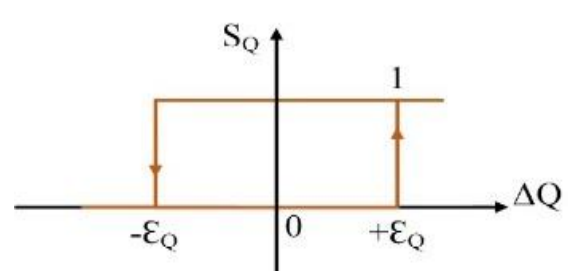

Figure 9. Hysteresis reactive power controller.

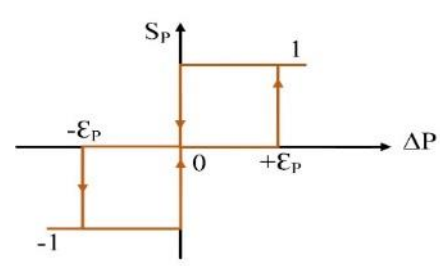

Figure 10. Hysteresis active power controller. 


\subsection{DPC Switching table}

Based on instantaneous input values such as the rotor flux vector sector and the state of the hysteresis output signals the switching table selects the next rotor voltage vector to get the estimated rotor flux (Table 1). Each rotor voltage vector corresponds to a specified switches state combination of the RSC [23].

Table 1. Switching table for DPC method of DFIG

\begin{tabular}{|c|c|c|c|c|c|c|c|}
\hline \multirow[b]{2}{*}{ Qs } & & \multicolumn{6}{|c|}{ Sector $\theta_{N}$} \\
\hline & Ps & $\begin{array}{c}1 \\
{\left[330^{\circ}, 30^{\circ}\right]}\end{array}$ & $\begin{array}{c}2 \\
{\left[30^{\circ}, 90^{\circ}\right]}\end{array}$ & $\begin{array}{c}3 \\
{\left[90^{\circ}, 150^{\circ}\right]} \\
\text { Volt }\end{array}$ & $\begin{array}{c}4 \\
{\left[150^{\circ}, 210^{\circ}\right]} \\
\text { age vector }\end{array}$ & $\begin{array}{c}5 \\
{\left[210^{\circ}, 270^{\circ}\right]}\end{array}$ & $\begin{array}{c}6 \\
{\left[270^{\circ}, 330^{\circ}\right]}\end{array}$ \\
\hline & 1 & $V_{5}$ & $V_{6}$ & $V_{1}$ & $V_{2}$ & $V_{3}$ & $\mathrm{~V}_{4}$ \\
\hline \multirow[t]{3}{*}{1} & 0 & $V_{7}$ & $V_{7}$ & $\mathrm{~V}_{7}$ & $V_{7}$ & $V_{7}$ & $\mathrm{~V}_{7}$ \\
\hline & -1 & $V_{3}$ & $V_{4}$ & $V_{5}$ & $V_{6}$ & $\mathrm{~V}_{1}$ & $\mathrm{~V}_{2}$ \\
\hline & 1 & $\mathrm{~V}_{6}$ & $V_{1}$ & V & $V_{3}$ & $V_{4}$ & $V_{5}$ \\
\hline \multirow[t]{2}{*}{0} & 0 & $V_{7}$ & $V_{7}$ & $V_{7}$ & $V_{7}$ & $V_{7}$ & $V_{7}$ \\
\hline & -1 & $V_{2}$ & $V_{3}$ & $V_{4}$ & $V_{5}$ & $V_{6}$ & $\mathrm{~V}_{1}$ \\
\hline \multicolumn{8}{|c|}{$\begin{array}{c}\mathrm{V}_{0}=[0 ; 0 ; 0] ; \mathrm{V}_{1}=[1 ; 0 ; 0] ; \mathrm{V}_{2}=[1 ; 1 ; 0] ; \mathrm{V}_{3}=[0 ; 1 ; 0] ; \mathrm{V}_{4}=[0 ; 1 ; 1] ; \mathrm{V}_{5}=[0 ; 0 ; 1] ; \mathrm{V}_{6}=[1 ; 0 ; 1] ; \\
\mathrm{V}_{7}=[1 ; 1 ; 1] ;\end{array}$} \\
\hline
\end{tabular}

\section{SIMULATION}

Table 2 shows in details the DFIG parameters used in this simulation. In this section, a $7.5 \mathrm{KW}$ DFIG have been simulated by MATLAB/Simulink. In order to observe the regulation behavior of our system Figure 1, two main tests have been applied, a) fixed wind profile operation mode and b) aleatory wind profile with MPPT control operation mode.

Table 2. Simulation settings

\begin{tabular}{lc}
\hline \multicolumn{2}{c}{ Simulated DFIG parameters } \\
\hline Rated power & $7.5 \mathrm{kw}$ \\
hub height & $43,5 \mathrm{~m}$ \\
Moment of inertia & $0.3125 \mathrm{~kg} \cdot \mathrm{m}^{2}$ \\
Gearbox Gain & 90 \\
$L_{S}=0.084 H, R_{S}=0.455 \Omega, L_{r}=0.081 \mathrm{H}, R_{r}=0.62 \Omega, M=0.078 \mathrm{H}, P=2, f=50 \mathrm{~Hz}$ \\
\hline
\end{tabular}

\subsection{Fixed wind profile operation mode (test a)}

In this first test, a fix wind speed is applied to the wind turbine blades. It generally consists on applying active and reactive power steps that will help us checking the decoupling between the DFIG two powers.

Figure 11 and Figure 12 shows that active and reactive power follows perfectly the reference ones. For Figure 13 the sinusoidal waveform of the stator currents is presented. In Figure 14 depicts the variation of the mechanical speed versus time. It tracks the wind but with a delay which is due the very fast variation of the wind against the slow dynamics of generator. Figure 15 shows the curve of the electromagnetic torque of the DFIG. The latter follows the variation of active power.

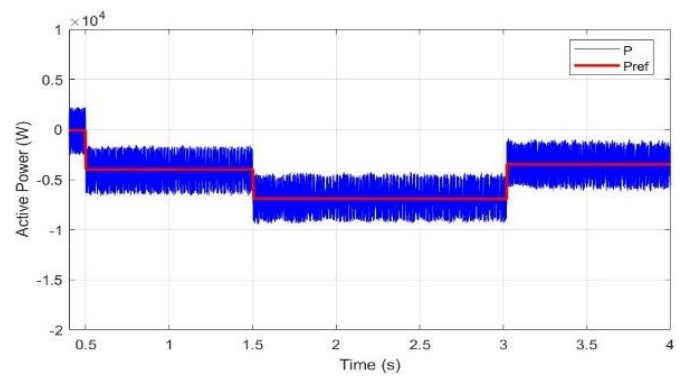

Figure 11. Profile of the stator active power

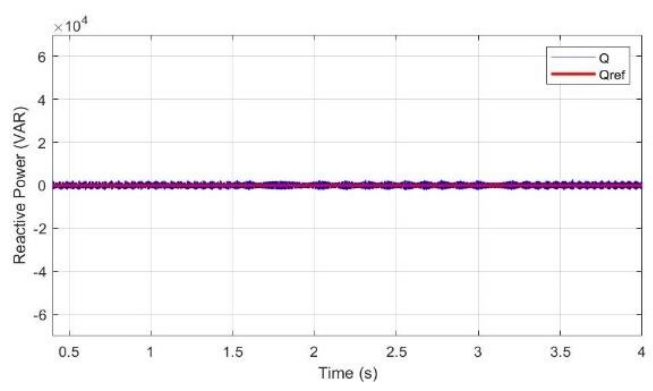

Figure 12. Profile of the stator reactive power 


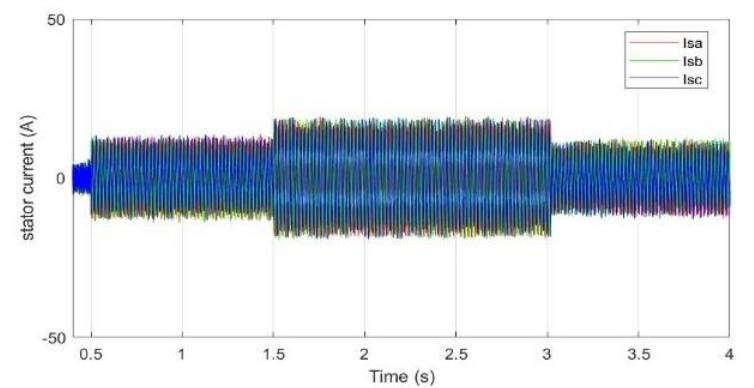

Figure 13. Stator current versus time

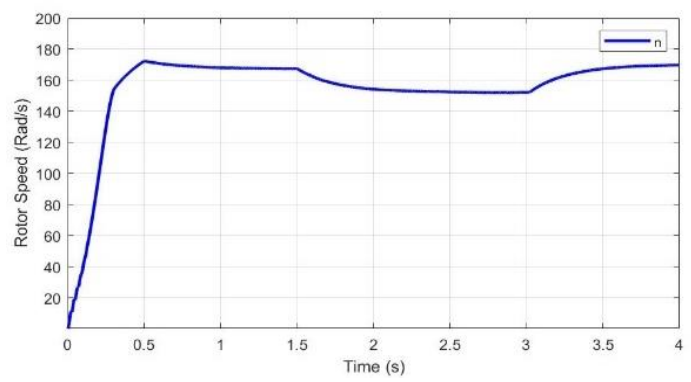

Figure 14. Variation of the rotor speed

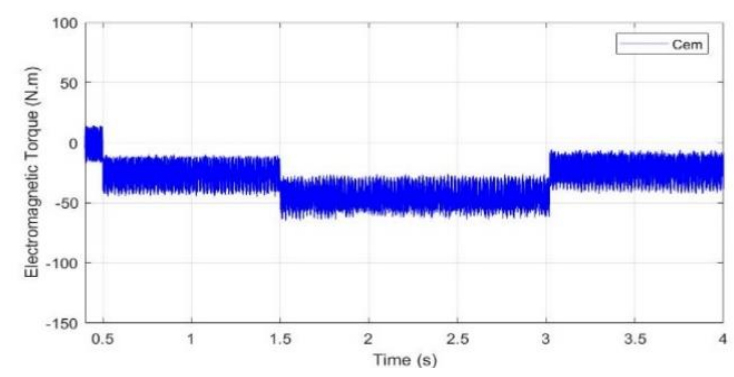

Figure 15. Time variation of the electromagnetic torque

\subsection{Aleatory wind profile with MPPT control operation mode (test b)}

In the results of the second test, the reference of the reactive power Figure 17 is set zero to ensure a unit power factor in the stator side and to optimize the quality of the energy delivered to the grid. While the reference of the active Figure 18 power makes it possible to keep the power coefficient of the wind turbine optimal whatever the wind speed Figure 16, these results are obtained thanks to the use of the MPPT technique. In Figure 19 displays the waveform of stator currents, we notice that the current magnitude varies as predicted, and the current frequency is reasonable. In Figure 20 exhibits that the mechanical speed follows the desired value computed based on the wind speed. With significant variations around the reference. This is because of the fast variations of the wind when we compare it to the generator dynamic. For the (Figure 21) shows, the electromagnetic torque of the generator varies according to that of the turbine that is a function of the wind speed.

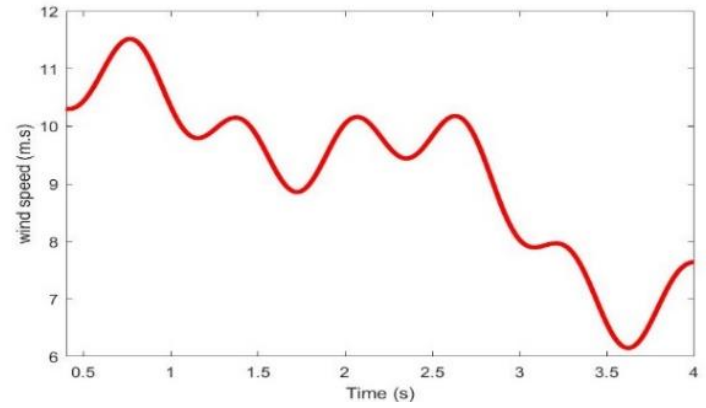

Figure 16. Wind speed profile

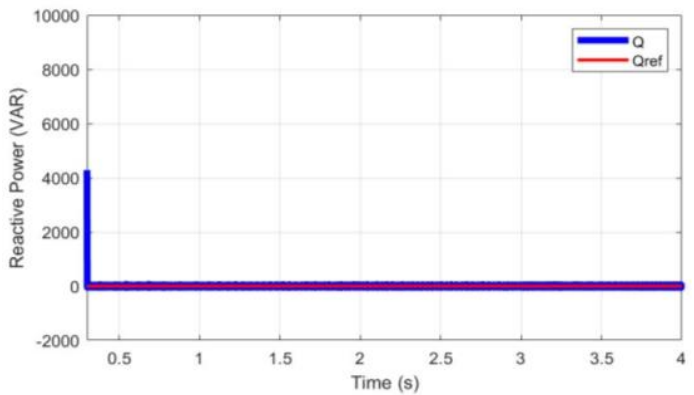

Figure 17. Profile of the stator reactive power 


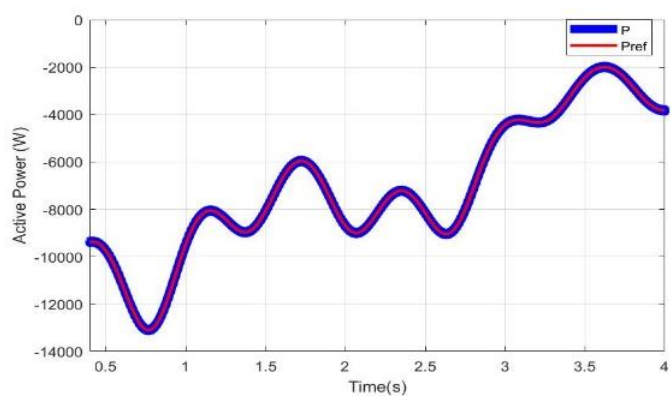

Figure 18. Profile of the stator active power

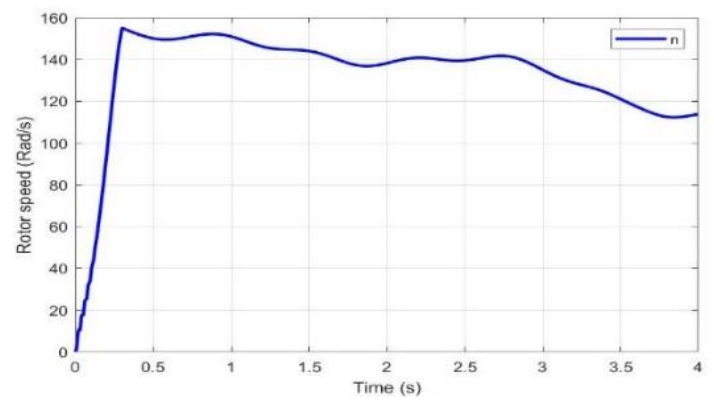

Figure 20. Time variation of the rotor speed

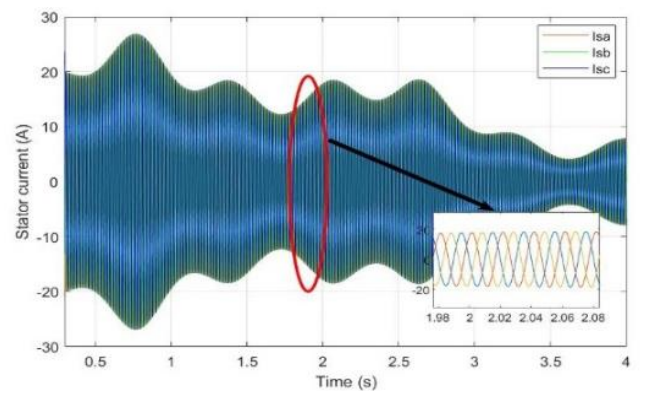

Figure 19. Stator current versus time

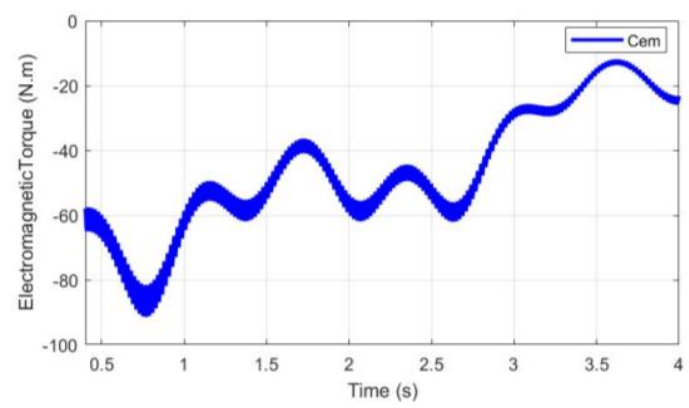

Figure 21. Time variation of the electromagnetic torque

\section{CONCLUSION AND FUTURE WORK}

In this paper, we have presented the modeling of a wind turbine and a doubly fed induction generator DFIG. Then, the DPC control strategy has been explained in detail. After that, the simulation results demonstrate the effectiveness of the DPC technique. One can notice that the power ripples are bounded and the generated power tracks the reference one for both the step the aleatory wind profiles. As a perspective of this work, we will compare the performances of DPC classic with those of fractional order sliding mode based DPC control by simulation and hardware implementation.

\section{REFERENCES}

[1] S. Benelghali, M. E. H. Benbouzid and J. F. Charpentier, "Comparison of PMSG and DFIG for marine current turbine applications," The XIX International Conference on Electrical Machines - ICEM 2010, Rome, 2010, pp. 1-6, DOI: 10.1109/ICELMACH.2010.5608118.

[2] D. Zhi and L. Xu, "Direct power control of DFIG with constant switching frequency and improved transient performance," in IEEE Transactions on Energy Conversion, vol. 22, no. 1, pp. 110-118, March 2007, DOI: 10.1109/ICELMACH.2010.5608118.

[3] El Ouanjli, N., Derouich, A., El Ghzizal, A., Chebabhi, A., Taoussi, M., "A comparative study between FOC and DTC control of the doubly fed induction motor (DFIM)," IEEE International Conference In Electrical and Information Technologies, ICEIT, pp. 1-6, DOI: 10.1109/EITech.2017.8255302.

[4] Mohammed Taoussi, Mohammed Karim, Badre Bossoufi1, Ahmed Lagrioui, and Mohammed El Mahfoud, "The fuzzy control for rotor flux orientation of the double-fed asynchronous generator drive," International Journal of Computers \& Technology, vol. 13, no. 8, pp. 4707-4722, 2013.

[5] Ouanjli, N. E., Derouich, A., Ghzizal, A. E., Motahhir, S., Chebabhi, A., Mourabit, Y. E., et al., "Modern improvement techniques of direct torque control for induction motor drives : a review," Prot. Control Mod. Power Syst, vol. 4, no. 1, 136-147, DOI: 10.1186/s41601-019-0125-5.

[6] Joaquín González Norniella, José M. Cano, Gonzalo Alonso Orcajo, Carlos H. Rojas, Joaquín Francisco Pedrayes, and Manés F. Cabanas, "Improving the dynamics of virtual-flux-based control of three-phase active rectifiers," in IEEE Transactions on Industrial Electronics, vol. 61, no. 1, pp. 177-187, Jan. 2014, DOI: 10.1109/TIE.2013.2245614.

[7] S. S. Lee and Y. E. Heng, "Table-based DPC for grid connected VSC under unbalanced and distorted grid voltages: Review and optimal method,” Renew. Sustain. Energy Rev., vol. 76, pp. 51-61, 2017. 
[8] S. Kouadria, E. M. Berkouk, Y. Messlem, and M. Denaï, "Improved control strategy of DFIG-based wind turbines using direct torque and direct power control techniques," J. Renew. Sustain. Energy, vol. 10, no 4, p. 304-306, 2018.

[9] F. Amrane, A. Chaiba, S. Mekhilef, "High performances of grid connected dfig based on direct power control with fixed switching frequency via mppt strategy using mrac and neuro-fuzzy control," Journal of Power Technologies, vol. 96, no. 1, pp. 27-39, 2016.

[10] Slootweg J.G., Haan W.H., Polinder G., and Kling W.L., "General model for representing variable speed wind turbines in power system dynamics simulations," IEEE Transactions on Power Systems, vol. 18, no. 1, pp. 144151, V, DOI: 10.1109/TPWRS.2002.807113.

[11] M. Rizo, A. Rodríguez, E. Bueno, F. J. Rodríguez and C. Girón, "Low voltage ride-through of wind turbine based on interior Permanent Magnet Synchronous Generators sensorless vector controlled," 2010 IEEE Energy Conversion Congress and Exposition, Atlanta, GA, 2010, DOI: 10.1109/ECCE.2010.5617956.

[12] El Ouanjli, N., Derouich, A., El Ghzizal, A., Bouchnaif, J., El Mourabit, Y., and Taoussi, M., et al., "Real-time implementation in dSPACE of DTC-backstepping for a doubly fed induction motor," The European Physical Journal Plus, vol. 134, no. 11, 5p. 66, 2019, DOI: 10.1140/epjp/i2019-12961-x.

[13] G. Abad, J. Lopez, M. A. Rodriguez, L. Marroyo, and G. Iwanski, "Doubly fed induction machine modeling and control for wind energy generation applications," Hoboken, NJ, USA: Wiley, 2011.

[14] M. Taoussi, M. Karim, D. Hammoumi, C. E. Bekkali, B. Bossoufi and N. E. Ouanjli, "Comparative study between backstepping adaptive and field-oriented control of the DFIG applied to wind turbines," 2017 International Conference on Advanced Technologies for Signal and Image Processing (ATSIP), Fez, 2017, pp. 16, DOI: 10.1109/ATSIP.2017.8075592.

[15] N. El Ouanjli, A. Derouich, A. El Gzizal, Y. El Mourabet, B. Bossoufi, M. Taoussi, "Contribution to the performance improvement of Doubly Fed Induction Machine functioning in motor mode by the DTC control," International Journal Power Electronics and Drive System (IJPEDS), vol. 8, no. 3, 2017, DOI: 10.11591/ijpeds.v8.i3.pp1117-1127.

[16] M. Taoussi, M. Karim, B. Bossoufi, D. Hmmoumi, C. Bakkali, A. Derouich and N. El Ouanjli, "Low-speed sensorless control for wind turbine system WSEAS transactions on systems and control," WSEAS Transactions on Systems and Control, vol. 12, pp. 405-417, 2017.

[17] N. El Ouanjli, S. Motahhir, A. Derouich, A. El Ghzizal, A. Chebabhi, and M. Taoussi, "Improved DTC strategy of doubly fed induction motor using fuzzy logic controller," Energy Reports, vol. 5, pp. 271-279, 2019, DOI: 10.1016/j.egyr.2019.02.001.

[18] Kairous D and Wamkeue R, "DFIG-based fuzzy sliding-mode control of WECS with a flywheel energy storage," Electric Power Systems Research, vol. 93, pp. 16-23, 2012, DOI: 10.1016/j.epsr.2012.07.002.

[19] N. El Ouanjli, A. Derouich, A. EL Ghzizal, S. Motahhir, Y. El Mourabit, M. Toussi, and et al., "Modern improvement techniques of direct torque control for induction motor drives - a review", Protection and Control of Modern Power Systems, vol. 4, no. 11, pp. 1-12, 2019, DOI: 10.1186/s41601-019-0125-5.

[20] A. Kadri, H. Marzougui, K. Omrani and F. Bacha, "Improved direct power control of a doubly fed induction generator-based wind energy conversion system," 2018 5th International Conference on Control, Decision and Information Technologies (CoDIT), Thessaloniki, 2018, pp. 707-712, DOI: 10.1109/CoDIT.2018.8394875.

[21] Zin, A. A. B. M., HA, M. P., Khairuddin, A. B., Jahanshaloo, L., and Shariati, O., "An overview on doubly fed induction generators' controls and contributions to wind-based electricity generation," Renewable and Sustainable Energy Reviews, vol. 27, pp. 692-708, 2013, DOI: 10.1016/j.rser.2013.07.010.

[22] H. R. Khoei and E. F. Shahraki, "Fuzzy logic based direct power control of induction motor drive," Bulletin of Electrical Engineering and Informatics, vol. 5, no. 3, pp. 296-306, 2016, DOI: 10.11591/eei.v5i3.538.

[23] B. Singh and N. K. Swami Naidu, "Direct Power Control of Single VSC-Based DFIG Without Rotor Position Sensor," in IEEE Transactions on Industry Applications, vol. 50, no. 6, pp. 4152-4163, Nov.-Dec. 2014.

[24] Y. Djeriri, A. Meroufel, A. Massoum, Z. Boudjema, "Direct power control of a doubly fed induction generator based wind energy conversion systems including a storage unit," Journal of Electrical Engineering, Vol.14, No.2, pp.1-8, 2014.

[25] M. A. Beniss, H. El Moussaoui, T. Lamhamdi, H. El Markhi, "Improvement of Power Quality Injected into the Grid by Using a FOSMC-DPC for Doubly Fed Induction Generator" in International Journal of Intelligent Engineering and Systems, Vol.14, No.2, pp.556, 2021, DOI: 10.22266/ijies2021.0430.50. 